\title{
AN EVALUATION OF THE MELLON MAYS UNDERGRADUATE FELLOWSHIP'S EFFECT ON PHD PRODUCTION AT NON-UNCF INSTITUTIONS
}

\author{
Sarah J. Prenovitz \\ Gary R. Cohen \\ Ronald G. Ehrenberg \\ George H. Jakubson \\ Working Paper 21451 \\ http://www.nber.org/papers/w21451
NATIONAL BUREAU OF ECONOMIC RESEARCH
1050 Massachusetts Avenue
Cambridge, MA 02138
August 2015

CHERI receives financial support from the Andrew W. Mellon Foundation but the conclusions we express here are strictly our own. The use of NSF data does not imply NSF endorsement of the research, research methods, or conclusions contained in this paper. The views expressed herein are those of the authors and do not necessarily reflect the views of the National Bureau of Economic Research.

NBER working papers are circulated for discussion and comment purposes. They have not been peerreviewed or been subject to the review by the NBER Board of Directors that accompanies official NBER publications.

(C) 2015 by Sarah J. Prenovitz, Gary R. Cohen, Ronald G. Ehrenberg, and George H. Jakubson. All rights reserved. Short sections of text, not to exceed two paragraphs, may be quoted without explicit permission provided that full credit, including (C) notice, is given to the source. 
An Evaluation of The Mellon Mays Undergraduate Fellowship's Effect on PhD Production at Non-UNCF Institutions

Sarah J. Prenovitz, Gary R. Cohen, Ronald G. Ehrenberg, and George H. Jakubson

NBER Working Paper No. 21451

August 2015

JEL No. I23

\begin{abstract}
The Mellon Mays Undergraduate Fellowship Program (MMUF) was established in 1988 to encourage underrepresented minority (URM) students to pursue $\mathrm{PhD}$ study with an eye towards entering academia. Fellows have completed $\mathrm{PhDs}$ at high rates relative to other students, but they are selected for their interest and potential, so this reflects both the effects of the program and the abilities of the students themselves. In order to understand one impact of the program we investigate its causal effect - how many of its fellows earned $\mathrm{PhDs}$ who would not have done so without the MMUF's support.

In this paper we use restricted access administrative data from the Mellon Foundation and the National Science Foundation's Survey of Earned Doctorates to investigate the effect of the MMUF on PhD completions by underrepresented minority students who graduate from participating institutions. We find no evidence that participation in the program causes a statistically significant increase in the $\mathrm{PhD}$ production rate of URM students and increases in larger than 0.4 percentage points lie outside a 95\% confidence interval using our unweighted baseline estimates. We also do not find evidence that increasing the intensity of the program by adding more fellows increases the $\mathrm{PhD}$ production rate, which is particularly notable as this estimate is upward-biased: the number of fellows likely reflects the strength of the candidate pool in a given year.
\end{abstract}

Sarah J. Prenovitz

Cornell Higher Education Research Institute 149 Ives Hall East

Ithaca, NY 14853-3901

sjp268@cornell.edu

Gary R. Cohen

Cornell Higher Education Research Institute

465 Uris Hall

Ithaca, NY 14853-3901

grc64@cornell.edu
Ronald G. Ehrenberg

Cornell Higher Education Research Institute 271 Ives Hall East

Ithaca, NY 14853-3901

and NBER

rge2@cornell.edu

George H. Jakubson

Cornell Higher Education Research Institute

257 Ives Hall

Ithaca, NY 14853-3901

George.Jakubson@cornell.edu 


\section{Introduction}

Colleges and universities seek to diversify their faculty along several dimensions, but find few underrepresented minorities ${ }^{1}$ in their hiring pool, with the problem worse in some fields than others. This is a manifestation of what is often referred to as the pipeline problem. Relatively few minorities pursue graduate study in many disciplines in the humanities, social sciences, physical sciences, or life sciences. If individuals do not enter PhD programs in a given field they will not emerge from the other end of the pipeline as potential faculty members.

The Mellon Minority Undergraduate Fellowship Program, since renamed the Mellon Mays Undergraduate Fellowship Program (MMUF), was established in 1988 with the goal of addressing this issue by encouraging underrepresented minorities to pursue graduate study in particular fields, with an eye towards ultimately entering academia. Participating schools select fellows from among their students, coordinate mentoring, and hold regular seminars which emphasize research and graduate school. Fellows receive stipends to allow them to conduct research as undergraduates. They are eligible to attend regional and national conferences at which they can present their own research, learn about that done by other fellows, and network. Fellows can also receive up to $\$ 10,000$ in loan repayments.

As of 2014, over 4,000 students have participated in the program; 506 have earned PhDs and another $665 \mathrm{PhDs}$ are in progress (Bengochea, 2013). As the program has expanded over time and as most $\mathrm{PhD}$ programs take at least 5 years to complete, if not substantially longer, this suggests an extremely high rate of $\mathrm{PhD}$ completion by MMUF scholars. A back of the envelope estimate suggests that about a quarter of MMUF students will eventually complete a PhD, compared with around 4 percent of underrepresented minority students graduating from MMUF institutions in years their school was not participating in the program. ${ }^{2}$

Anecdotal evidence suggests that the MMUF may play a large role in the ultimate $\mathrm{PhD}$ completion of its participants. MMUF administrators report struggling to recruit undergraduate candidates because few students have considered the possibility of entering academia, and fellows cite their research experiences, relationships with mentors, and connections with other fellows as crucial to their decision to pursue a $\mathrm{PhD}$ and their ultimate success in completing one (Rose, 2012). However, fellows presumably apply to the program because of their own interest and are selected based on their potential as scholars, so the high rate of $\mathrm{PhD}$ completion reflects both this selection and the effects of the program. Indeed, in a 2007 survey, 67 percent of current and former fellows responded that they would have or might have aspired to earn a $\mathrm{PhD}$ absent

\footnotetext{
${ }^{1}$ Underrepresented minorities are defined as those who identify neither as non-Hispanic White nor as Asian.

${ }^{2}$ If we assume that the program selected the same number of fellows in each year for a total of 4,000 as of 2014 and their distribution of completion times was the same as non-white non-Asian students who completed a bachelors' degree in a MMUF field in 1985-1989 and went on to complete a PhD, we would expect to observe about half of those PhDs which will be completed within 20 years of graduation. As approximately one in eight MMUF fellows has completed a PhD, this suggests that about a quarter of MMUF fellows will do so eventually. The program has grown over time, which would make this back of the envelope calculation an underestimate. However, fellows also have incentives and supports to complete degrees more quickly, so degrees completed so far may represent a larger proportion of those that will eventually be completed.
} 
the program (Rose, 2012). The MMUF may still help students turn these goals into reality, and inspire those who would not have otherwise considered an academic career to explore one, but fellows are probably quite different from other students in their underlying propensity to complete a $\mathrm{PhD}$. It also may be the case that students who have already completed the program overstate their chances of pursuing $\mathrm{PhDs}$ in its absence. Without a doubt some current and former fellows would have aspired to earn $\mathrm{PhDs}$ in the program's absence, and so it is useful to determine to what extent fellows' high $\mathrm{PhD}$ completion rate is a result of the program.

We address this issue by estimating the effect of a school's MMUF participation per se and the intensity of participation on the number and rate of $\mathrm{PhD}$ completions by under-represented minority (URM) students. ${ }^{3}$ By investigating the outcomes of all URM students at an institution we are able to avoid this sample selection problem, and address the effect of the program on its medium-run goal. Institutions have joined the program gradually over time, and this allows us to control for time trends and cross-institution variation using institution and year fixed effects. However, due to the lengthy nature of $\mathrm{PhD}$ programs we do not observe the completions of many of those who will eventually earn a $\mathrm{PhD}$, especially in later cohorts. Time to degree is in general longer for URM students than for other students, exacerbating the problem. We estimate the size of this truncation using data from those who graduated in the early years of our dataset, and conduct the bulk of our analyses using this adjusted data.

While our focus is on a single fellowship, many other programs share the broad goals and methods of the MMUF. To our knowledge these programs have not been evaluated in the economics literature, but several prior studies in the education literature have explored their effects. Most of this work has been purely correlational, which is problematic as students who participate are quite different from those who do not. Other analyses have used propensity score matching to construct an appropriate control group of students, but participants may still differ from non-participants in important but unobservable ways (e.g. Eagan et al., 2013). We contribute to this literature by using a design that allows us to avoid the issue of student selection, addressing problems of truncation in degree data, and analyzing a program whose causal effects are unknown.

We estimate the average effect of an institution's participation in the MMUF program and find no significant effect of the program when considering only the MMUF schools. These findings persist when we account for truncation and when we add control groups constructed through propensity score matching. We also find no effect of adding an additional fellow or increasing the percentage of URM students who are fellows. This is particularly notable as these estimates may suffer from positive selection bias: institutions are able to move funds from year to year, awarding more fellowships in years with relatively strong applicant pools and fewer in other

\footnotetext{
${ }^{3}$ The Mellon Foundation considers throughput - the entry of its fellows into PhD programs - to be a key metric for assessing the undergraduate components of the program (Bengochea 2013). While the PhD completion rate of the URM student body as a whole is not an explicit program goal, the best available data for causal analysis limit our focus to completion and to an estimate of the treatment effect on an average URM student at a participant school rather than a Mellon Mays fellow specifically. We believe that this average treatment effect is an appropriate metric for evaluation, as it is closely linked to the pipeline problem that is the raison d'etre for the MMUF, and any increase in fellows' PhD completion that results from the program should also increase the overall number of URM students completing PhDs.
} 
years. We conclude that there is no evidence that the MMUF program has a causal effect on URM PhD completion rates. Because we are evaluating a small program using aggregate data, it is possible the program has an effect that is too small for us to distinguish. It may also be that the MMUF is important to participants in other ways that do not increase the number of PhDs, or that our truncation adjustments do not adequately capture changes in the time to degree over time.

The rest of this paper proceeds as follows. Section 2 provides background and further detail on the program structure and history. Section 3 describes our data and methods. Section 4 presents results and section 5 discusses these results and our conclusions.

\section{Background and Program Structure}

\subsection{Background}

Colleges and universities pursue faculty diversity for several reasons. First, if minority faculty members are better at connecting with minority students, either in the classroom or as mentors and role models, their presence might be important to the persistence and graduation rates of minority students. There is some evidence that minority students are more likely to persist in STEM majors if they have an introductory STEM course that is taught by a minority professor (Price, 2010), and that gaps between minority and non-minority community college students in pass rates, grades, and courses dropped are smaller when classes are taught by professors who are minorities themselves (Fairlie, Hoffmann, \& Oreopoulos, 2011). Second, to the extent that raw teaching and research potential are distributed throughout the population, hiring underrepresented minorities at a very low rate implies that institutions are losing out on important groups of potential faculty. Finally, diversity may be pursued for its own merits. It can stimulate a dynamic academic atmosphere, enriching the work and lives of all faculty and students; address societal inequalities; or bring academic attention to a wider range of issues that would otherwise be the case.

Institutions that seek to diversify faculty are constrained by the small number of underrepresented minorities completing PhDs. In 2011, 6.14 percent of the US citizens or permanent residents earning a $\mathrm{PhD}$ reported that they were Black, while 6.3 percent reported that they were Hispanic (National Science Foundation, 2012). These numbers are substantially higher than at the inception of the MMUF (4.8 percent and 3.6 percent in 1985 respectively), but still quite low relative to the US population, which was 12.3 percent Black and 16.7 percent Hispanic in 2011 (Census, 2011). There is also substantial variation across fields, with Black students earning 13 percent of $\mathrm{PhDs}$ in education but only 3 percent of those in physical sciences, and Hispanic students earning 8 percent of PhDs in social sciences and 4.5 percent of those in the physical sciences (NSF, 2012). While departments in some fields might find a diverse range of job candidates others are still constrained in their ability to hire from underrepresented minority groups.

\subsection{The Mellon Minority/Mays Undergraduate Fellowship Program}

The MMUF program began with eight institutions, which joined the program in late 1988 and recruited their first fellows in the spring of 1989. Additional cohorts joined in 1989, 1992, 1996, 
2000, and 2007. A group of Historically Black Colleges and Universities has participated since 1989 through a consortium administered by the United Negro College Fund (UNCF). ${ }^{4}$ Not counting this consortium, 42 institutions participated in the program in 2014. A table of the institutions in our sample and the year they joined the program appears in appendix table A1.

Participating institutions select fellows, generally targeting students in the spring of their sophomore year. Schools are provided with funding for up to five fellows per year, though they are able to select more fellows in some years by moving funds from one school year to another, or if students who were previously selected drop out of the program. In the early years of the program fellowships were restricted to those belonging to underrepresented minority groups. However, in response to concerns from participating institutions about the legality and ethics of affirmative action and other race-based programs, eligibility was extended in 2003 to students of all backgrounds who were committed to the program's goal of increasing the presence of underrepresented minorities in academia (Mellon Foundation, 2003). In addition to supporting the diversity goals of the program, fellows must be pursuing a major in one of the Mellondesignated fields. These span the humanities, social sciences, and hard sciences, but do not include all majors. A list of the fields for 2000 and 2008 is included in appendix table A2.

Students apply directly to the fellowship program at their institution. Although each institution has considerable discretion in evaluating applicants, they are asked to consider the student's field and either minority status or commitment to the program's goals, as well as academic promise, interest in an academic career, and potential as a mentor. Once selected as fellows, students work with mentors and attend seminars at their home institution. Because of the decentralized nature of the program, each participating school decides how to implement the mentorship and seminar components. Mentors are intended to act as graduate school advisers - much as a pre-law or pre-med adviser would - and to oversee the student's independent research. Seminars are in general focused on research and preparation for graduate school, and are intended also to allow students to form a group identity. Fellows also receive stipends both during the school year and over the summer to allow them to focus on research rather than paid work, and to potentially allow for fieldwork or study at another institution over the summer. The MMUF administers regional and national conferences at which students can present work, be exposed to the work done by other fellows, and network with current and former fellows.

After college graduation, fellows who attend graduate school in a designated field can be eligible to participate in seminars and conferences, apply for grants expressly for former undergraduate fellows, and receive loan forgiveness. The seminars and conferences include an annual conference similar to that attended by undergraduates as well as programs focused on writing grants and dissertations. There are also retreats for those in the dissertation-writing phase. Loans taken out for undergraduate and graduate study are eligible for loan forgiveness, up to a total of $\$ 10,000$ if the student completes a PhD in a Mellon-designated field. Loan forgiveness is only available to those who attend a $\mathrm{PhD}$ or terminal Masters' program in one of the designated fields, and requires the fellow to begin his or her program within about three years of graduation or submit an appeal.

\footnotetext{
${ }^{4}$ Our analyses exclude the UNCF consortium for reasons described in the methodology section.
} 


\section{Data and Methods}

\subsection{Data and Sample}

Our analyses use data from the Integrated Post-Secondary Education Data System (IPEDS), a restricted access version of the National Science Foundation's Survey of Earned Doctorates (SED), and restricted access administrative data from the Mellon Foundation. The IPEDS includes institution-level information on enrollment, costs and finances, faculty, and other characteristics for all colleges and universities in the United States that receive federal funding. Data is provided by institutions, and has been collected in 1987 and then annually since 1989. The Higher Education General Information System (HEGIS), the predecessor to IPEDS, includes data for earlier years, dating back to 1966. Many of the variables in the HEGIS data are the same or similar to those in IPEDS, but HEGIS includes less information and was collected less frequently. From these systems we obtain institution-level information on the number of students completing bachelors' degrees by race/ethnicity, gender, and field from 1985 through 2005. We also use a larger set of institutional characteristics, drawn from the IPEDS Delta Cost Project data, in order to construct matched comparison groups.

The Survey of Earned Doctorates (SED) is an annual census of $\mathrm{PhD}$ completers in the United States, sponsored by six federal entities and administered since 1957. The SED achieves a high response rate, with 92 percent of those earning $\mathrm{PhDs}$ responding in 2012, although item response rates are somewhat lower (National Science Foundation 2013). It includes information on demographics, undergraduate and graduate study, and career plans. We use data from the SED for those who completed a PhD between 1985 and 2011. From this population we count the number of individuals who have completed a $\mathrm{PhD}$ by undergraduate institution, year of bachelors' degree, minority status, field, and gender. We also obtain counts of the number completing a PhD a given number of years after the bachelors' degree by subgroup and year of bachelors' degree. This data on the distribution of times to $\mathrm{PhD}$ completion for the early cohorts in our sample is used to adjust for the fact that later cohorts have fewer years to complete a PhD, and thus their number of PhD completers is understated due to sample truncation.

The Mellon Foundation's data provides counts of MMUF program fellows at each participant institution in each year. The distribution of fellows by year and school is depicted in Figure 1. Although most institutions had 3-6 fellows in most years of participation there is considerable variation in the number of fellows. In general, the smallest schools in terms of URM enrollment are more likely to have fewer than 5 fellows in multiple years. We use this data to calculate the 'dosage' of the program within the overall URM population of each cohort at each institution. We then use this dosage and the raw numbers of participants in extensions to our base model to account for the fact that we would expect the treatment effect of this relatively small program to be more pronounced - and easier to detect - at institutions where a greater proportion of the URM population participated.

Our analyses focus on the 32 non-UNCF institutions that selected their first fellows by 2005 . The UNCF institutions are excluded because program participation at each UNCF school in any particular year is far more varied than at the other U.S. institutions with most UNCF institutions having zero participants in any given year. We are concerned that we would be unable to discern the effect of the program at these schools, and that the participation of a given institution in the program in a particular year may be a strong signal about the propensity of its students in that 
cohort to attend graduate school. We limit our analysis to cohorts that graduated by 2005, as more recent graduates had completed relatively few PhDs by 2011.

Most institutions in our sample are privately controlled (Table 1). A slight majority grant doctorates, with the rest about evenly split between those that only grant bachelor's degrees and those that grant masters or first professional degrees. In 1985, before the MMUF began, the average institution produced slightly over 1,000 bachelors' degrees, about 14 percent of which went to URM students. About 11 percent of graduates went on to complete a PhD by 2011, with rates fairly similar for URM and non-URM students. By 2005 the average institution produced about 1,300 bachelor's degrees, with about 23 percent going to URM students. Only 1.7 percent of these graduates completed a PhD by 2011, which is unsurprising given that they only had six years to do so.

We focus primarily on the sample of URM students, based on the assumption that the MMUF has the potential to affect $\mathrm{PhD}$ completion rates for those students who are eligible to participate, but not those who are not eligible. In some analyses we include the $\mathrm{PhD}$ completion rate for nonminority students as a control variable. While the introduction of a new fellowship opportunity could decrease competition for existing programs, change campus culture, or inspire the peers of fellows to pursue a different path, we do not expect these factors to be large, particularly as the program is relatively small, and its benefits are restricted to fellows. To the extent that the benefits of the MMUF spill over to those who are not eligible to participate, our estimates would understate the full effect of the MMUF on PhD completion.

Our initial plan was to restrict the analysis to the $\mathrm{PhD}$ completion rate in MMUF fields, based on similar reasoning. We were forced to abandon this plan for several reasons. First, IPEDS reports only one major per BA completer until 2000, and two in later years. Thus students with more than one major before 2000, or more than two after, could be eligible for the program but not be identifiable in the data as being eligible. Second, a sizable number of students switch fields between $\mathrm{BA}$ and $\mathrm{PhD}$, so those identified in the numerator and denominator of our rate calculation are not necessarily the same students. Third, although more recent data contains detailed information on undergraduate majors, HEGIS and IPEDS used a very broad coding scheme for completers' fields (2-digit CIP) until 1996. As a result we are unable to distinguish some of the MMUF fields in these early data. Finally, even with perfect data we would not be able to define which students were eligible for the program based on fields, both because institutions had some discretion to decide whether a field closely related to a MMUF field was eligible, and because documentation on which fields were eligible before 2000 does not exist. Instead we restrict the sample by broad categories of fields - arts and sciences; arts, sciences, and engineering; and all fields - rather than using a more specific definition of eligible fields. All MMUF fields from 2000 and 2008 fall into arts and sciences, which includes humanities, social sciences, life sciences, and physical sciences. The arts, sciences, and engineering group adds engineering fields. The all fields category includes all BAs or doctorates, including those in arts, humanities, and engineering, as well as fields such as education and business.

\subsection{Method}

Using the number of $\mathrm{BA}$ completers and $\mathrm{PhD}$ completers, we compute $\mathrm{PhD}$ completion rates, calculated as the percentage of graduates of a given institution in a given year who have since gone on to earn a PhD. This is done separately for minority and non-minority students, by the 
broad field groups. Here $B A s J_{i t}$ is the number of individuals in group $\mathrm{j}$ who completed bachelor's' degrees at institution i in year $\mathrm{t}$, and $P h D s J_{i t}$ is the number of those individuals who completed a $\mathrm{PhD}$ by 2011, when our information on PhD completion ends. RateJ ${ }_{i t}$ is the eventual $\mathrm{PhD}$ completion rate for institution $\mathrm{i}$, group $\mathrm{j}$, graduation year $\mathrm{t}$.

(1) RateJ $_{i t}=\frac{\text { PhDSJ }_{i t}}{B A S J_{i t}}$

In our baseline specification we regress the $\mathrm{PhD}$ completion rate for minorities $\left(\right.$ RateM $\left._{i t}\right)$ on whether the institution was participating in the program when that cohort was eligible to be selected to participate $\left(M M F_{i t}\right)$. We also include graduation year fixed effects $\left(T_{t}\right)$ in order to control for variations over time in the share of bachelors' graduates completing PhDs nationally, and institution fixed effects $\left(I_{i}\right)$. This gives us an estimate of the effect of an institution's participation on the $\mathrm{PhD}$ completion rate.

(2) Rate $_{i t}=\beta M M F_{i t}+T_{t}+I_{i}+u_{i t}$

We also estimate the baseline equation with the addition of the rate for non-minority students $\left(\right.$ RateNM $\left.M_{i t}\right)$ included as an explanatory variable. If the coefficient on this term were restricted to be equal to 1 this would be equivalent to a standard difference-in-difference specification with year and institution fixed effects. Empirically we find that this coefficient is not equal to 1, so use this more flexible specification instead. Standard errors are clustered at the institution level. We present unweighted results as well as results that weight observations by the number of underrepresented minority students completing bachelors' degrees to improve the precision of our estimates.

\section{Results}

\subsection{Baseline Estimates}

Results from the baseline specification are displayed in the first two columns of Table 2. Despite the benefits of the MMUF felt by its participants, the model is unable to detect any impact of the program on the $\mathrm{PhD}$ production rates of URM graduates. We find no significant effect of the program on $\mathrm{PhD}$ completions, and point estimates are mostly negative and very small. An increase in the rate of $\mathrm{PhD}$ completion in the arts and sciences larger than 0.4 percentage points lies outside a 95\% confidence interval using unweighted results, as does an increase larger than 0.8 percentage points using weights. Results are similar when we include the non-minority $\mathrm{PhD}$ completion rate (Table 2 columns 3 and 4 ) and when considering degrees in all fields.

Because more schools have joined the MMUF program over time, and later cohorts suffer greater truncation, our baseline model likely understates the impact of the program. For example, a student who completed his or her bachelors' degree in 2002 has only 9 years to complete a PhD by 2011, the last year of data available to us on $\mathrm{PhD}$ completions. This number is below the median time to degree for some fields, and thus will miss more than half of the potential PhDs. Because PhDs in progress at the time of measurement are treated as though they will never be completed, this causes it to appear as though the $\mathrm{PhD}$ production rate is declining over time. Then, because the MMUF program is introduced throughout our sample period, participation effects are confounded with truncation effects. URM students take longer on average to complete $\mathrm{PhDs}$, as illustrated in Figure 2, which presents the distribution of $\mathrm{PhD}$ completion times for all 
SED respondents who completed their BA in the US and are US citizens or permanent residents. ${ }^{5}$ As a result, including the non-minority rate does not eliminate the problem of truncation.

In order to improve this estimate we implement two strategies to adjust for the fact that we do not observe $\mathrm{PhDs}$ in progress. The first takes the distribution of time to $\mathrm{PhD}$ that prevailed in the first 5 years of our sample and applies it to the remainder of the data. That is, we predict how many of those who have completed bachelor's degrees but are not recorded as having completed $\mathrm{PhDs}$ them will eventually complete a $\mathrm{PhD}$, and use that to form our estimate of the $\mathrm{PhD}$ production rate. We do this separately for URM and non-URM students. Students from these early cohorts have at least 20 years post-college to finish their graduate degrees, so truncation is likely to be a much smaller problem. If this method captures truncation patterns accurately it allows us to compare $\mathrm{PhD}$ completion rates as of the same number of years from $\mathrm{BA}$ graduation, putting all cohorts on an equal footing. The disadvantage of this approach is that it makes the strong assumption that the time-to-PhD distribution is fixed over time. ${ }^{6}$ To address this latter concern, we estimate a second model where we allow the truncation pattern to change over time. We do this by estimating a quadratic model on early cohorts for each number of years from BA $\mathrm{y}$, where $\mathrm{t}$ is the number of years from 1985:

\section{(3) $\operatorname{Pr}($ Complete within y years $)=\alpha_{0}+\alpha_{1} t+\alpha_{2} t^{2}$}

We then apply this to the rest of the sample as before. Similarly to the previous approach, we would like to fit the prediction model to a set of data where truncation is less problematic. We therefore run specifications where this prediction model is applied to the first ten years of data (1985-1994). ${ }^{7}$ As in the first model, degree completion patterns are estimated separately for URM and non-minority students, and applied to both PhD completion rates. Table 3 displays results after correcting for truncation. The results of the first, 'fixed' truncation model are presented in the first two columns, while those from ten-year quadratic model is presented in columns 3 and 4. Both methods of correcting for truncation produce similar results - adopting the MMUF does not appear to have a significant effect on an institution's URM PhD completion rate.

Our analyses so far have used only the MMUF schools, using those institutions in years before they began participating in the program as controls. Although our estimates are fairly precise, we would like to introduce additional control observations to increase precision further. Estimating the program effect using the sample of all U.S. institutions would greatly overstate the effects of the program, as many MMUF institutions were selected for participation in the program specifically because they are high-quality colleges and universities where the PhD production rate is already high. Instead we select two control groups constructed using the Stata command psmatch2 to estimate the probability that each institution would be selected to participate in the MMUF program based on its observable characteristics. The first control group uses 1-nearestneighbor matching to select the non-treated institution with the nearest propensity score to each

\footnotetext{
${ }^{5}$ This figure understates the difference in degree completion time somewhat, as URM students make up a larger proportion of PhD completions in later cohorts, and members of later cohorts with particularly long times to degree do not appear in the data.

${ }^{6}$ In fact, formal statistical tests that we conducted suggest that this assumption is not strictly true.

${ }^{7}$ We investigated a similar quadratic model using the first five years of data, and the results were qualitatively similar.
} 
treated institution as an appropriate control. ${ }^{8}$ We match with replacement, meaning that a nontreated school can serve as the match for more than one treated school if no other non-treated school is a 'better' control. The second matched control group is constructed using kernel matching to construct an appropriate control institution from a combination of non-participating schools. A list of the variables employed in the matching routine appears as Appendix Table A3, and a list of the schools in the 1-nearest neighbor match appears as Appendix Table A4.

Results from the matching procedures are presented in Table 4. These estimates employ the 10year flexible truncation correction described above and include the non-minority $\mathrm{PhD}$ completion rate as a control. We do not weight observations by the number of URM graduates in these specifications, as weights are not used in constructing the matched comparison schools. We find no evidence that participation affected the $\mathrm{PhD}$ completion rate in arts and sciences, but using the nearest neighbor match suggests program participation decreased the rate for arts, sciences and engineering and all fields. Although it is possible that these significant estimates are due to chance, the pattern of negative coefficients suggests that participation decreases the PhD completion rate for fields outside of the arts and sciences.

\subsection{Estimates of Program Intensity}

In addition to changes in whether a school was participating in the MMUF in a given year there is considerable variation in the size of a MMUF cohort for a given school. This variation should improve our ability to identify the effect of the program and offer an estimate of the effect of changing the size of the program at an institution. We do this first by estimating the effect of increasing the number of fellows $(M M F e l l o w s i t)$ on the number of PhDs completed by URM students $\left(P h D s M_{i t}\right)$. As in the baseline model we include year fixed effects $\left(T_{t}\right)$ and institution fixed effects $\left(I_{i}\right)$. We include a control for the number of BAs completed by minority students $\left(B A s M_{i t}\right)$ and the non-minority completion rate $\left(\right.$ RateNM $\left.M_{i t}\right)$. We estimate with a negative binomial model to account for the fact that the dependent variable is a count. ${ }^{9}$

(4) $P h D s M_{i t}=\beta_{1}$ RateNM $M_{i t}+\beta_{2} B A s M_{i t}+\beta_{3} M M F e l l o w s s_{i t}+T_{t}+I_{i}+u_{i t}$

We find uniformly positive point estimates for the effect of adding an additional fellow, but these estimates are not significant at conventional levels (Table 5). If correct, our estimates would imply that each student added to the MMUF program adds 0.01 to $0.02 \mathrm{PhDs}$ that otherwise would not have been completed - an extremely small effect. Adjusting for truncation using the 10-year adjustments increases the point estimates slightly, but they remain insignificant and quite small. This null finding is particularly interesting as the estimates include both the effect of adding a fellow and whatever factors drove a school to add that fellow, which likely includes the strength of a given cohort.

As an alternative to estimating the effect of adding a given number of fellows, we estimate the following, where Dosage $_{i t}$ is defined as the number of fellows from graduation cohort $t$ at institution $i$ divided by the number of URM students in that cohort and institution.

\footnotetext{
${ }^{8}$ We estimated the same models with Malahnobis-metric matching and obtained qualitatively similar results.

${ }^{9}$ Although a Poisson distribution would also account for this feature of the data, the negative binomial fits our data better.
} 


\section{(5) Rate $_{i t}=\beta_{1}$ RateNM $_{i t}+\beta_{2}$ Dosage $_{i t}+T_{t}+I_{i}+u_{i t}$}

Increasing the dosage of the program appears to decrease the PhD completion rate for all fields, although this association is not significant for other field groups, and becomes insignificant once we adjust for truncation using the 10 -year model. The negative relationship could result from an actual causal mechanism or it may be a statistical artifact of the relationship between URM population size and dosage - if the number of fellows remains approximately the same an increase in the number of URM students will decrease the dosage. If the number of URM students is small enough very small changes in the number of URM students can generate considerable differences in the dosage. In order to disentangle the two possibilities we broke the sample into three groups based on the size of the URM population and repeated our estimates with each group separately. This exercise produced negative point estimates for small schools in all three field groupings and positive point estimates for medium and large schools, none of which are significant (results available from authors upon request). We interpret this result as suggesting that the negative result is the product of the relationship between dosage and cohort size.

\subsection{Robustness}

We explore the possibility that the adoption of the MMUF program is not random by investigating whether there is any difference in $\mathrm{PhD}$ completion rates up to 5 years before and up to 5 years after program adoption. For this analysis we focus on the data adjusted using the 10year truncation model, and weight observations by URM cohort size. We find some evidence of an increase in $\mathrm{PhD}$ production rates for arts and sciences two cohorts before the first cohort was eligible to participate (Table 6). This is particularly interesting as these students were in the spring of their senior year when the MMUF began recruiting students at their institution. It may suggest that institutions adopted the MMUF also pursued other avenues to encourage PhD-going among URM students. However, as there is no effect for the cohort one year ahead of the first MMUF cohort it appears that these initiatives were short-lived.

We also conduct our baseline estimates with institution-specific linear trends to allow for the possibility that each institution follows its own trend. The results are similar to those found without the inclusion of time trends and are available from the authors upon request.

\section{Conclusion}

We describe the Mellon Mays Undergraduate Fellowship Program, the supports it offers its participants, and its growth over time. Using a census of undergraduate completions from the Department of Education as well as a census of $\mathrm{PhD}$ completions from the National Science Foundation, we then attempt to estimate the causal effect of the MMUF program on the rate of PhD production of URM bachelors' graduates at participant schools. We find no statistically significant effect of an institution's participation in the program and a 95\% confidence interval rules out an effect of more than about 0.4 percentage points using our baseline estimates. We also find no significant effect of increasing the number or percentage of fellows, although we do find predominantly positive point estimates that would suggest an effect of about 0.01-0.02 additional $\mathrm{PhDs}$ for each additional fellow. In both cases these estimates are extremely small, in contrast to the large percentage of MMUF fellows who complete $\mathrm{PhDs}$. 
Several factors could explain our null findings. First, the program may simply not do much to increase the number of $\mathrm{PhDs}$ produced by URM students. If the program selects the brightest and most motivated students it may benefit those who would have already been likely to attend graduate school and earn PhDs even in its absence. This would not necessarily mean that the MMUF is unimportant - the program could increase the quality of the institutions fellows attend for their doctoral studies, improve dissertations produced or job skills gained, speed completion, or improve the financial position of graduates. Any of these effects could increase the number of URM students entering academia, in addition to being beneficial to fellows, but we are not able to capture them in our data: the Survey of Earned Doctorates is collected at the time of $\mathrm{PhD}$ completion and thus is limited in its ability to measure most variables pertaining to careers in academia. Second, the small size of the program at each institution might inhibit our ability to discover an overall effect with statistical models: if only a handful of students in each year are MMUF participants, the largest possible effect the program could have on $\mathrm{PhD}$ production rates will similarly be small. Despite our rather precise estimates we may be failing to detect a real, but small, effect of the program. This is less likely given the insignificant effects we find for Increases in program intensity, but those are still complicated by the substantial noise of $\mathrm{PhD}$ completions by non-fellows. Finally, our truncation correction could simply be incorrect. If the true truncation pattern is not fit or well approximated by any of our models we may fail to find results where any exist. The true distribution of degree completion times is unknowable until all degrees can be observed, so we cannot rule out this possibility.

Our findings are most generalizable to expansions of the MMUF to institutions relatively similar to those that already participate or increases in the size of the program at MMUF institutions. Many MMUF schools are quite unlike the average U.S. institution and were selected in part based on their high PhD-going rates and a perception that many students had the potential and preparation for a career in academia. However, the program has also been implemented at institutions selected more for the diverse populations they serve (e.g. CUNY schools), where overall student preparation may not be as high. It would be interesting to extend our study to the subsample of the CUNY schools and the state universities that were later introduced to the program, but that shrinks the pool of observations too greatly to draw meaningful conclusions from the data. There are also other programs that are broadly similar to the MMUF (such as the McNair Scholars Program) to which these same empirical methods could be applied.

Despite the caveats listed above, we hope our findings will prove instructive to designers of future policies. If a program aims to maximize its impact on the number of students achieving any particular benchmark it is important not only to design the program to benefit its recipients but also to select those recipients on the margin of the desired outcome. 


\section{References}

Bengochea, Armando I. (2013). "25th Anniversary Review of the Mellon Mays Undergraduate Fellowship (MMUF).” Unpublished Manuscript.

Eagan, M. Kevin., Hurtado, Sylvia, Chang, Mitchell, Garcia, Gina, Herrera, and Garibay, Juan (2013). "Making a difference in science education: The impact of undergraduate research programs. American Education Research Journal, 50(4), 683-713. doi: 10.3102/0002831213482038

Fairlie, Robert, Hoffmann, Florian, and Oreopoulos, Philip (2011). "A community college instructor like me: Race and ethnic interactions in the classroom." NBER Working Paper 17381. DOI: $10.3386 /$ w 17381

Mellon Foundation (2003). "The Andrew W. Mellon Foundation: Report from January 1, 2003 through December 31, 2003.” New York: Mellon Foundation. Available at [http://www.mellon.org/news_publications/annual-reports-essays/annualreports/content2003.pdf]. Accessed 4/24/14.

Mellon Mays Undergraduate Fellowship (2013). "About." Available at [www.mmuf.org/about]. Accessed 4/28/14.

National Science Foundation (2012). "US Citizen and Permanent Resident Doctorate Recipients, by Race/Ethnicity and Broad Field of Study: Selected Years, 1991-2011.” Available at [http://www.nsf.gov/statistics/sed/2011/data_table.cfm]. Accessed 4/24/14

National Science Foundation (2013). Survey of Earned Doctorates. Available at [http://www.nsf.gov/statistics/srvydoctorates/\#sd]. Accessed 4/24/14.

Price, Joshua (2010). "The effects of instructor race and gender on student persistence in STEM fields." Economics of Education Review, 29, 901-910. DOI: 10.1016/j.econedurev.2010.07.009

Rose, Brad (2012). "Program Review: The Mellon Mays Undergraduate Fellowship (MMUF) Program.” Wellesley, MA: Brad Rose Consulting. Available at [http://bradroseconsulting.com/wp-content/uploads/2012/10/MMUF-Program-Review.pdf]. Accessed 4/28/14.

United States Census Bureau (2011). Annual Estimates of the Resident Population by Sex, Race, and Hispanic Origin for the United States: April 12010 to July 1, 2011 (NC-ECT2011-03). Available at [http://www.census.gov/popest/data/national/asrh/2011/tables/NC-EST2011-03.xls]. Accessed $6 / 8 / 15$.

United States Department of Education. Institute of Education Sciences, National Center for Education Statistics (2014). The Integrated Postsecondary Education Data System.

United States Department of Education. National Center for Education Statistics. Higher Education General Information Survey (HEGIS) 
Figure 1.

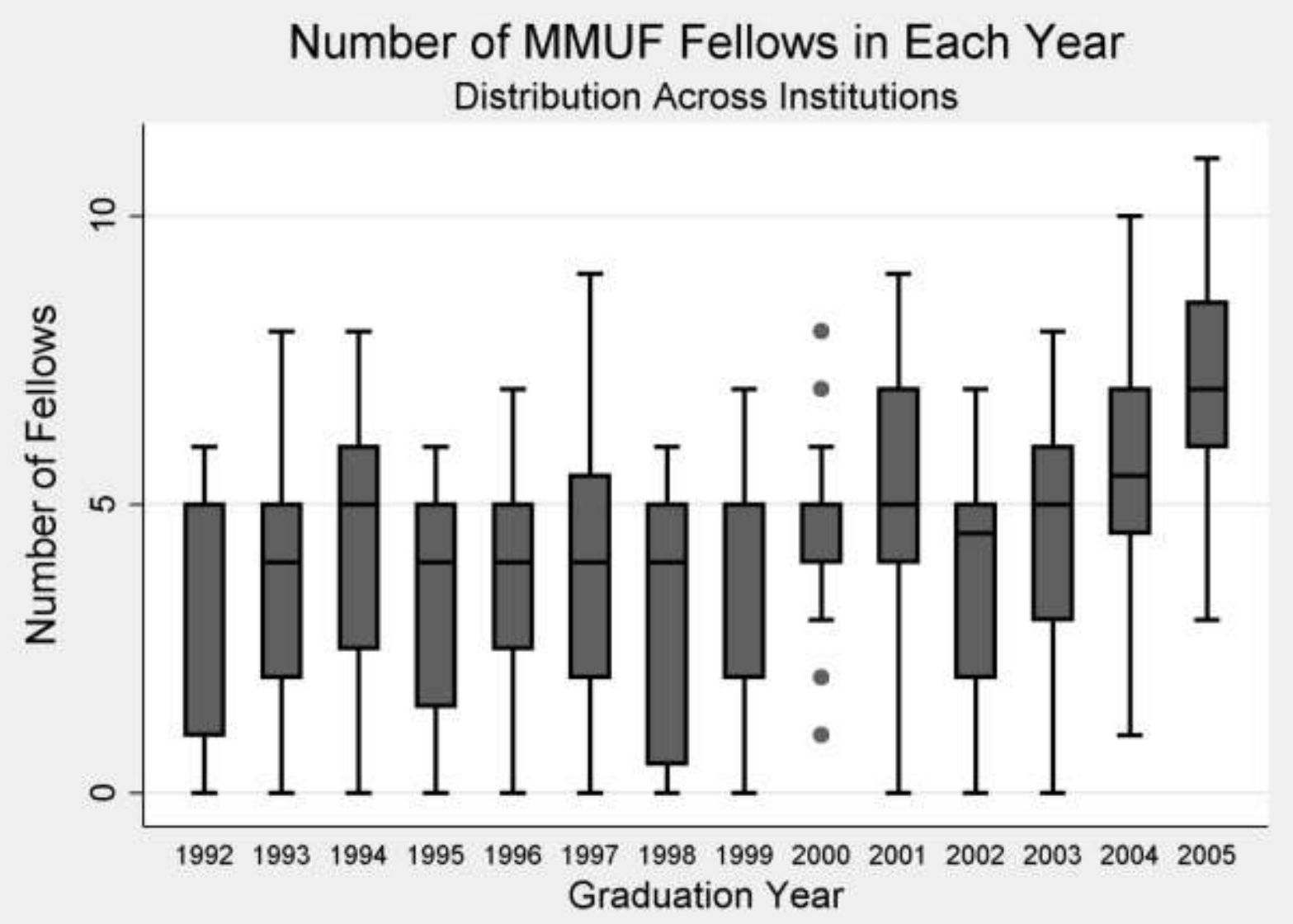

Source: Administrative data provided by the Mellon Foundation 
Figure 2.

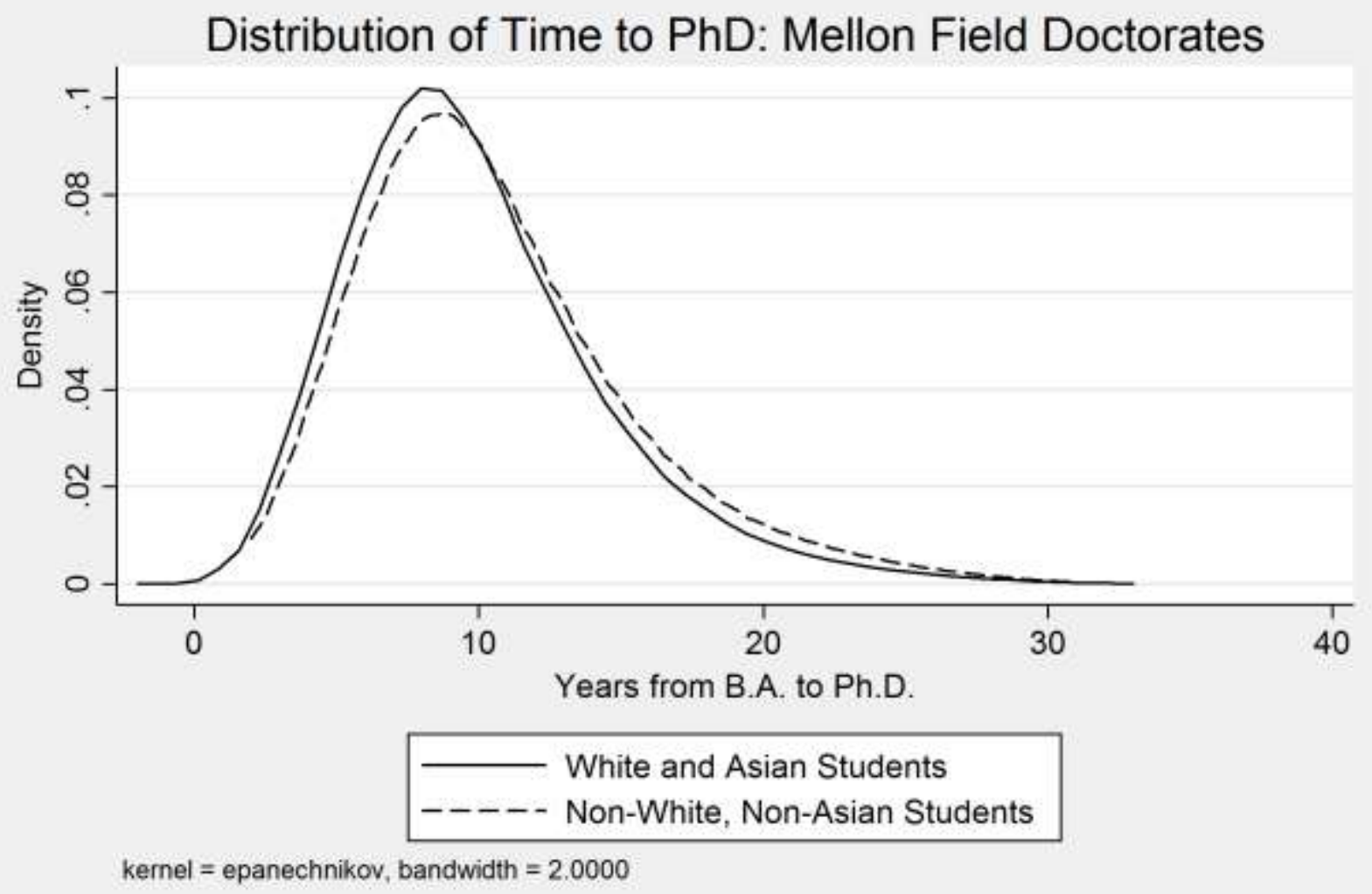

Source: Authors' calculations based on the Survey of Earned Doctorates

Notes: Sample includes all US Citizens and Permanent Residents who completed a PhD in one of the MMUF fields between 1980 and 2011, completed a BA in the US, and responded to the Survey of Earned Doctorates 
Table 1. Characteristics of the non-UNCF institutions participating in the MMUF program by 2005

\begin{tabular}{|c|c|c|c|}
\hline & $\mathrm{N}$ & Mean & SD \\
\hline Public Control & 32 & 0.125 & 0.336 \\
\hline \multicolumn{4}{|l|}{ Highest Degree } \\
\hline Bachelors & 32 & 0.219 & 0.420 \\
\hline Doctorate & 32 & 0.594 & 0.499 \\
\hline Masters/First professional & 32 & 0.188 & 0.397 \\
\hline \multicolumn{4}{|l|}{ Characteristics as of 1987} \\
\hline Enrollment & 32 & $8,901.4$ & 7768.5 \\
\hline Tuition and fees per student & 32 & 8834.223 & 3335.806 \\
\hline Percent of students who are undergraduates & 32 & 0.734 & 0.217 \\
\hline \multicolumn{4}{|l|}{1985 Graduates } \\
\hline All BAs & 32 & 1,046 & 727 \\
\hline URM BAs & 32 & 214.1 & 495.9 \\
\hline non-URM BAs & 32 & 831.7 & 610.6 \\
\hline Proportion of Bas awarded to URM students & 32 & 0.145 & 0.202 \\
\hline $\mathrm{PhD}$ completion rate & 32 & 0.106 & 0.078 \\
\hline $\mathrm{PhD}$ completion rate - URM & 32 & 0.110 & 0.127 \\
\hline PhD completion rate - non-URM & 31 & 0.110 & 0.075 \\
\hline Ratio of URM to non-URM rate & 31 & 0.930 & 0.508 \\
\hline \multicolumn{4}{|l|}{2005 Graduates } \\
\hline All BAs & 31 & 1,323 & 922 \\
\hline URM BAs & 31 & 333.1 & 269.6 \\
\hline non-URM BAs & 31 & 989.5 & 702.5 \\
\hline Proportion of Bas awarded to URM students & 31 & 0.229 & 0.12 \\
\hline $\mathrm{PhD}$ completion rate & 31 & 0.017 & 0.03 \\
\hline $\mathrm{PhD}$ completion rate - URM & 31 & 0.010 & 0.02 \\
\hline $\mathrm{PhD}$ completion rate - non-URM & 31 & 0.019 & 0.03 \\
\hline Ratio of URM to non-URM rate & 30 & 0.476 & 0.68 \\
\hline
\end{tabular}


Table 2. Effect of MMUF participation on the URM PhD completion rate - unadjusted model

\begin{tabular}{llcccc}
\hline & & $(1)$ & $(2)$ & $(3)$ & $(4)$ \\
\hline (a) & A\&S & 0.013 & -0.002 & 0.013 & -0.002 \\
& & $(0.018)$ & $(0.005)$ & $(0.018)$ & $(0.005)$ \\
(b) A\&S + Eng. & -0.011 & -0.003 & -0.011 & -0.004 \\
& & $(0.010)$ & $(0.005)$ & $(0.010)$ & $(0.005)$ \\
(c) All Fields & -0.015 & -0004 & -0.015 & -0.005 \\
& & $(0.009)$ & $(0.004)$ & $(0.009)$ & $(0.004)$ \\
\hline & & & & $\checkmark$ \\
& Weights & & & $\checkmark$ & $\checkmark$ \\
\hline \hline
\end{tabular}

Notes: Twelve models are reported: for each model, the dependent variable is the rate of $\mathrm{PhD}$ completion among those non-white, non-Asian students who graduated from an institution in a particular year, with degrees in a particular group of fields as indicated by (a), (b), and (c). All models include year and institution fixed effects. Specifications (3) and (4) include the comparable rate for white and Asian students. Weights are by size of institution in number of URM BA completers. Estimation is by OLS. Standard errors in parentheses are clustered by institution.

A * indicates significance at the 5\% confidence level, and a $\uparrow$ the $1 \%$ confidence level. 
Table 3. Effect of MMUF participation on the URM PhD completion rate - truncation adjusted

\begin{tabular}{llcccc}
\hline & & $(1)$ & $(2)$ & $(3)$ & $(4)$ \\
\hline (a) & A\&S & 0.027 & 0.001 & 0.006 & -0.003 \\
& & $(0.031)$ & $(0.004)$ & $(0.014)$ & $(0.004)$ \\
(b) & A\&S + Eng. & -0.004 & -0.003 & -0.013 & -0.004 \\
& & $(0.006)$ & $(0.004)$ & $(0.009)$ & $(0.004)$ \\
(c) & All Fields & -0.008 & -0.004 & -0.015 & -0.004 \\
& & $(0.006)$ & $(0.003)$ & $(0.008)$ & $(0.004)$ \\
\hline & Weights & & $\checkmark$ & & $\checkmark$ \\
& Simple adjustment & $\checkmark$ & $\checkmark$ & $\checkmark$ & $\checkmark$ \\
\hline \hline
\end{tabular}

Notes: Twelve models are reported: for each model, the dependent variable is the predicted rate of $\mathrm{PhD}$ completion among those non-white, non-Asian students who graduated from an institution in a particular year, with degrees in a particular group of fields as indicated by (a), (b), and (c). All models include the comparable rate for white and Asian students, as well as year and institution fixed effects. The simple adjustment is a truncation adjustment under the assumption that the time to $\mathrm{PhD}$ pattern from 1985-1989 persists throughout the sample. The 10-year adjustment is a truncation adjustment with a quadratic model in time fit to the first ten years of data. Weights are by size of institution in number of URM BA completers. Estimation is by OLS. Standard errors in parentheses are clustered by institution.

$\mathrm{A} *$ indicates significance at the $5 \%$ confidence level, and a $\uparrow$ the $1 \%$ confidence level. 
Table 4: Effect of MMUF participation on the URM PhD completion rate - matched comparison

\begin{tabular}{llcc}
\hline & & $(1)$ & $(2)$ \\
\hline (a) & A\&S & -0.008 & -0.001 \\
& & $(0.007)$ & $(0.005)$ \\
(b) & A\&S + Eng. & $-0.019^{*}$ & -0.006 \\
& & $(0.008)$ & $(0.004)$ \\
(c) & All Fields & $-0.018 \dagger$ & -0.007 \\
& & $(0.006)$ & $(0.004)$ \\
\hline & & \\
& 1 Nearest neighbor & $\checkmark$ & $\checkmark$ \\
\hline
\end{tabular}

Notes: Six models are reported: for each model, the dependent variable is the predicted rate of $\mathrm{PhD}$ completion among those non-white, non-Asian students who graduated from an institution in a particular year, with degrees in a particular group of fields as indicated by (a), (b), and (c). Prediction is a truncation adjustment with a quadratic model in time fit to the first ten years of data. All models include the comparable rate for white and Asian students, as well as year and institution fixed effects. Estimation is by OLS. Standard errors in parentheses are clustered by institution.

$\mathrm{A} *$ indicates significance at the $5 \%$ confidence level, and a $\uparrow$ the $1 \%$ confidence level. 
Table 5. Effect of intensity of MMUF participation on URM PhD production

\begin{tabular}{llcccc}
\hline & & $(1)$ & $(2)$ & $(3)$ & $(4)$ \\
\hline (a) & A\&S & 0.017 & 0.021 & 0.083 & $-0.240^{*}$ \\
& & $(0.012)$ & $(0.013)$ & $(0.063)$ & $(0.096)$ \\
(b) & A\&S + Eng. & 0.015 & 0.021 & 0.458 & 0.045 \\
& & $(0.012)$ & $(0.013)$ & $(0.257)$ & $(0.104)$ \\
(c) & All Fields & 0.011 & 0.019 & 0.508 & 0.130 \\
& & $(0.011)$ & $(0.012)$ & $(0.338)$ & $(0.172)$ \\
\hline & Count & $\checkmark$ & $\checkmark$ & & \\
& Dosage & & & $\checkmark$ & $\checkmark$ \\
& Unadjusted & $\checkmark$ & & $\checkmark$ & \\
& 10-year adjustment & & $\checkmark$ & & $\checkmark$ \\
\hline \hline
\end{tabular}

Notes: Twelve models are reported: for each model, the dependent variable is the predicted number of $\mathrm{PhD}$ completions or predicted $\mathrm{PhD}$ completion rate among those non-white, nonAsian students who graduated from an institution in a particular year, with degrees in a particular group of fields as indicated by (a), (b), and (c). Prediction is a truncation adjustment with a quadratic model in time fit to the first ten years of data. All models include the comparable rate for white and Asian students, as well as year and institution fixed effects. Columns (1) and (2) present estimates of the effect of adding an additional fellow on the number of $\mathrm{PhDs}$ completed. Column (1) uses a negative binomial model and column (2) uses OLS. Columns (3) and (4) present estimates of the effect of increasing the dosage of the program on $\mathrm{PhD}$ completion rates, using OLS. Standard errors in parentheses are clustered by institution.

$\mathrm{A} *$ indicates significance at the $5 \%$ confidence level, and a $\uparrow$ the $1 \%$ confidence level. 
Table 6. Event study of MMUF adoption

\begin{tabular}{rrrrrrrrrrrr}
\hline & \multicolumn{1}{c}{$\mathrm{t}-5$} & $\mathrm{t}-4$ & $\mathrm{t}-3$ & $\mathrm{t}-2$ & $\mathrm{t}-1$ & $\mathrm{t}$ & $\mathrm{t}+1$ & $\mathrm{t}+2$ & $\mathrm{t}+3$ & $\mathrm{t}+4$ & $\mathrm{t}+5$ \\
\hline Arts and & 0.003 & 0.005 & 0.004 & $0.020 *$ & 0.010 & -0.003 & 0.006 & 0.009 & 0.009 & 0.009 & 0.005 \\
Sciences & $(0.008)$ & $(0.009)$ & $(0.011)$ & $(0.008)$ & $(0.006)$ & $(0.004)$ & $(0.008)$ & $(0.007)$ & $(0.007)$ & $(0.007)$ & $(0.007)$ \\
& & & & & & & & & & & \\
Arts Sci. & 0.009 & $0.016^{*}$ & 0.005 & 0.005 & 0.003 & -0.004 & 0.007 & 0.011 & 0.011 & 0.007 & 0.003 \\
and & & & & & & & & & & & \\
Eng. & $(0.005)$ & $(0.007)$ & $(0.009)$ & $(0.008)$ & $(0.008)$ & $(0.004)$ & $(0.007)$ & $(0.006)$ & $(0.006)$ & $(0.006)$ & $(0.006)$ \\
& & & & & & & & & & & \\
All & 0.001 & 0.003 & 0.005 & 0.013 & 0.009 & -0.004 & 0.007 & 0.009 & 0.009 & 0.005 & 0.003 \\
Fields & $(0.007)$ & $(0.008)$ & $(0.008)$ & $(0.007)$ & $(0.005)$ & $(0.004)$ & $(0.006)$ & $(0.005)$ & $(0.005)$ & $(0.005)$ & $(0.005)$ \\
\hline \hline
\end{tabular}

Notes: Thirty three models are reported: for each model the dependent variable is the predicted rate of $\mathrm{PhD}$ completion among those non-white, non-Asian students who graduated from an institution in a particular year relative to the first MMUF cohort at that institution (t). Prediction is a truncation adjustment with a quadratic model in time fit to the first ten years of data. All models include the comparable rate for white and Asian students, as well as year and institution fixed effects. Estimation is by OLS. Standard errors in parentheses are clustered by institution. $\mathrm{A} *$ indicates significance at the $5 \%$ confidence level, and a $\uparrow$ the $1 \%$ confidence level. 


\section{Appendix}

Table A1. Non-UNCF Mellon Mays Institutions Participating by 2005

\begin{tabular}{ll}
\hline Institution Name & First Year of Participation \\
\hline Barnard College & 1998 \\
Bowdoin College & 1993 \\
Brown University & 1994 \\
Bryn Mawr College & 1990 \\
California Institute of Technology & 1994 \\
Carleton College & 1989 \\
Columbia University & 1997 \\
Cornell University & 1990 \\
CUNY Brooklyn College & 1990 \\
CUNY City College & 1990 \\
CUNY Hunter College & 1990 \\
CUNY Queens College & 1990 \\
Dartmouth College & 1990 \\
Duke University & 1998 \\
Emory University & 2001 \\
Harvard University & 1990 \\
Haverford College & 2001 \\
Macalester College & 2001 \\
Oberlin College & 1989 \\
Princeton University & 1990 \\
Rice University & 1994 \\
Smith College & 2000 \\
Stanford University & 1989 \\
Swarthmore College & 1990 \\
University of Chicago & 1990 \\
University of Pennsylvania & 1990 \\
University of Southern California & 1994 \\
Washington University in Saint Louis & 1994 \\
Wellesley College & 1990 \\
Wesleyan University & 1991 \\
Williams College & 1990 \\
Yale University & 1990 \\
\hline
\end{tabular}


Table A2. Mellon-Designated Fields

Fields as of 2000

Anthropology and Archaeology

Area/Cultural/Ethnic/Gender Studies

Art History

Classics

Demography, Geography and Population Studies

Earth/Environmental/Geological Science and Ecology

English

Ethnomusicology

Film, Cinema and Media Studies (theoretical focus)

Foreign Languages and Literatures

Linguistics

History

Literature

Mathematics

Musicology

Philosophy

Oceanographic/Marine/Atmospheric/Planetary Science

Physics and Astronomy

Political Theory

Religion and Theology

Theater (non-performance focus)

2008 Field Additions

Computer Science

Sociology 
Table A3. Predictor variables for propensity score matches

Institution is Public

Fall Enrollment

Ratio of Undergraduates to All Students

Ratio of Female Undergraduate Students to All Undergraduate Students

Ratio of Full-Time Undergraduate Students to All Undergraduate Students

Ratio of Full-Time Female Faculty to All Female Faculty

Ratio of Female Faculty to All Faculty

Ratio of Full-Time Faculty to All Faculty

Ratio of Faculty to All Staff

Avg. 9-10 Month Salary for All Male Faculty

Avg. 9-10 Month Salary for All Female Faculty

Ratio of Undergraduate STEM Completions to All Undergraduate Completions

Ratio of Undergraduate Humanities Completions to All Undergraduate Completions

Tuition and Fees per Student

Endowment Income per Student

Total Revenues per Student

Instruction Expenditure per Student

Academic Support Expenditure per Student

Student Services Expenditure per Student

Total Scholarship Expenditures per Student

Percentage of Student Body that is Black

Percentage of Student Body that is Asian

Percentage of Student Body that is Hispanic 
Table A4. Matched control institutions, nearest neighbor match

Baptist Bible College of Pennsylvania

Carnegie Mellon University

Case Western Reserve University

Davidson College

Georgetown University

Goucher College

Le Moyne-Owen College

Long Island University

North Carolina State University at Raleigh

Northwestern University

Radcliffe College

Saint Basil's College

San Diego State University

San Francisco Conservatory of Music

Seton Hall University

Smith College

Southern University Agricultural and Mechanical College

University of Massachusetts at Amherst

University of Michigan, Ann Arbor 